\title{
Research-led Course Design and Practice of English for Academic Purposes in Chinese-Foreign Cooperatively-run Schools
}

\author{
Lijuan Jiao \\ Southampton International College \\ Dalian Polytechnic University \\ Dalian, Liaoning, China \\ E-mail: jiaolijuan1972@163.com
}

\author{
Jihui Qu \\ School of Art and Design \\ Dalian Polytechnic University \\ Dalian, Liaoning, China \\ E-mail: qujh@dlpu.edu.cn
}

\author{
Xiuli Ge* \\ Southampton International College \\ Dalian Polytechnic University \\ Dalian, Liaoning, China \\ E-mail: gexl@dlpu.edu.cn
}

\begin{abstract}
In the past few decades, many Chinese-foreign cooperatively-run schools have gained the approval of the People's Republic of China and developed rapidly. In these schools, traditional English teaching mode emphasizing the knowledge instruction can no longer meet the requirements of international education. The research-led teaching and learning model refers to the learning process that starts from a problem or phenomenon and helps students to actively explore knowledge about the problem and solve the problem through independent research or group cooperation under the teacher's guidance. Research-led teaching and learning is a teaching model that can effectively stimulate students' interests in learning, train their critical thinking and integrating knowledge, and improve their ability to learn independently and solve practical problems. Some highly specialized Chineseforeign cooperatively-run schools have higher requirements for academic English and the students' English level in listening, speaking, reading and writing. This article starts with the necessity of research-led EAP teaching mode in Chineseforeign cooperatively-run schools, summarizes the course design and practice of Chinese-foreign cooperation in running schools between the University of Southampton and Dalian Polytechnic University, exemplifies some specific research-led projects to explain the EAP course design and practice in this Chinese-foreign cooperatively-run schools, and provide some experience for other similar education institutions.
\end{abstract}

Keywords-research-led learning and teaching, English for Academic Purposes, Chinese-foreign cooperation in running schools

\section{INTRODUCTION}

In recent years, Chinese-foreign cooperation in running schools has made great progress. It has played an important role in promoting the reform of education system, innovating talent cultivation models, and serving major national development strategies. The social recognition and international influence of these educational institutions have been continuously improved. Until June 2018, there are a total of 2,342 Chinese-foreign cooperative institutions and projects, of which a total of 1,090 institutions and projects above undergraduate level [1]. The requirements for academic English in Chinese-foreign cooperative institutions have also increased accordingly. Traditional college English and general English teaching can no longer meet the professional English requirements of Chinese-foreign cooperative institutions. In the era of knowledge economy, knowledge has been expanded at an unprecedented speed
This poses a challenge to the traditional college education emphasizing knowledge instruction. College students not only need to learn theoretical knowledge, but also learn practical ways concerning their majors. The research-led teaching and learning model refers to the learning process that starts from a problem or phenomenon and helps students to actively explore knowledge about the problem and solve the problem through independent research or group cooperation under the guidance of the teacher. Research-led teaching and learning is a teaching model that can effectively stimulate students' interests in learning, train their critical thinking, and improve their ability to learn independently and solve practical problems. Some highly specialized Chineseforeign cooperatively-run schools have higher requirements for academic English and the comprehensive ability of students' English listening, speaking, reading and writing. Xi'an Jiaotong-Liverpool University has gained a lot of outstanding experience in the practice of the research-led teaching and learning model, which has provided valuable experience for many Chinese-foreign cooperative education institutions in China. This article summarizes the course design and practice of English for Academic Purposes (EAP) in Southampton International College of Dalian Polytechnic University, which is a cooperative programme between the University of Southampton and Dalian Polytechnic University. Based on the practice of EAP in this Chineseforeign cooperative school, this article aims to exemplify some specific research-led projects and provide some experience for other similar education institutions.

\section{The NeCESSITy of ACADEMIC ENGLish TEACHING IN CHINESE-FOREIGN COOPERATIVELY-RUN SCHOOLS}

According to Outline of China's National Plan for Medium and Long-term Education Reform and Development (2010-2020), college English is endowed with the instrumental nature for specific purpose to fully implement China's educational policy, further deepen the reform of college English teaching, and improve the overall quality of English teaching. Students can learn academic or professional English related to their majors or future jobs to gain the ability to communicate in academic or professional fields. The teaching goal of college English is to enable the students to use English effectively in their study, life, social communication and future work, and to meet the needs of the country, society and personal development. It can be seen that college English should focus on the improvement 
of the learners' academic or professional English ability, so that students can use English effectively in their future jobs.

English for Specific Purposes (ESP) originated in the 1960s, which refers to English related to a specific occupation or discipline. The teaching objectives and teaching content of the course are mainly or entirely determined by the learners' requirements for English in terms of function and practice. English for General Purposes (EGP) refers to the basic English knowledge taught in schools. It emphasizes the basic language structure of learning, including vocabulary and grammar, and aims to cultivate students' English skills in listening, speaking, reading, writing and translation. EGP teaching in colleges and universities mainly focuses on the improvement of the above-mentioned basic language skills, while ESP teaching focuses on satisfying the needs of students' professional learning or future work. EGP is for the purpose of pure language learning, while EAP is more specific and is set up to help learners to meet specific professional needs. There are some misunderstandings about the relationship between EGP and EAP. Some believe that professional English is relatively difficult and it is not suitable for some language learners with weak foundation for English. Therefore, learners' practical needs for language learning are usually ignored when too much emphasis is placed on the study of some profession-related articles or the recitation of some professional vocabulary. The current situation in Chinese colleges and universities is that not all the colleges and universities are capable of providing all professional courses in English. Therefore, the EAP teaching model requires that the teaching objectives be formulated in accordance with the training plan, clarifying whether the EAP course is a supplement to the professional course or an extension of general English, and then determining the class time and practical links of the EAP course.

EAP is different from professional English or scientific English. Indeed, it is necessary to clarify the contribution of general English in improving students' humanistic literacy and effectively implement academic English teaching as well. There is already theoretical support and practical experience about EAP teaching. At present, there are different opinions on EGP and EAP in China, mainly including "substitution" and "complement". Those who advocate "substitution" believe that EAP can completely replace EGP in college English teaching, which may only apply to some schools that are not suitable for carrying out EAP thoroughly. Those who believe that EAP is a supplement to EGP should not only emphasize the contribution of EGP to students' essential English skills. In fact, they need to notice the significance of EAP in meeting students' needs in their future work and study. According to the university's characteristics and students' English proficiency, the corresponding EGP and EAP courses can be reasonably configured to maximize the contribution of college English courses in China's higher education and even the development of the country. Wen Qiufang and others believe that the two are complementary to each other [2]. Cai Jigang and others believe that EAP will gradually replace EGP. Cai Jigang believes that EAP teaching is the method for the development of college English teaching in China, and EGP should not be regarded as general English [3]. Wang Shouren and others argue that general English can be used as the leading factor and academic English can be used as an experiment in some colleges and universities.
Wang Shouren points out that most colleges and universities should not regard the passing rate of the CET- 4 or CET- 6 as the ultimate goal and the improvement of students' overall and comprehensive ability as the most important teaching goals $[4,5]$. In order to further deepen the English teaching reforms carried out by colleges and universities in recent years, whether it is the introduction of network technology or the improvement of students' listening and speaking skills, they are all reforms carried out within language teaching such as curriculum and teaching methods. The internationalization of higher education requires Chinese colleges and universities to adjust their teaching programs and goals correspondingly. The purpose of English teaching is not only to teach the learners a specific foreign language, but also to improve their overall humanistic quality. English is the main language of international economic and cultural exchanges. A qualified college student should have the ability to read English literature, write English papers, listen to classes in English, and participate in academic discussions. However, current college English teaching is greatly restricted by many factors such as teachers' ability, curriculum setting, class size, etc. Unlike English majors, college English should be more instrumental, that is, the main value of college English is to help college students master professional knowledge in English. Overemphasizing the humanity of language teaching, that is, strengthening the introduction of humanistic knowledge and the comparison of Chinese and foreign cultures will go against the original purpose of college English, which aims to cultivate the students' ability to learn independently and conduct research related to their professional knowledge in English.

China's college English teaching reform is to improve the instrumental nature of English and meet the needs of the society for talent cultivation. College English teaching has gradually changes teaching ideas and turns to professional services, aiming to help students improve their ability to solve professional problems and conduct academic research in English. The proportion of academic English in future English teaching should be appropriately increased. Adopting appropriate teaching methods to promote the teaching and learning of academic English is a serious problem in the current reform of college English teaching. EGP and EAP are complementary to each other, which can effectively help students consolidate their English foundation and make the transition to academic English learning faster. Colleges and universities should design personalized syllabus according to their actual situation and construct a multi-modal teaching model for EAP courses.

\section{RESEARCH-LED ENLGiSH For ACADEMIC PuRPoses TEACHING MODEL}

Based on learners' needs and ultimate goals of college English, research-led teaching and learning focuses on cultivating students' ability to use English for their future work, and emphasizes learners' individual needs. A lively language learning atmosphere is built in a research-led English class to help improve the students' independent learning ability, adapt to the needs of national and social development, and effectively enhance students' ability in using academic English [6,7].

First of all, EAP teaching is the model supported by the College English Teaching Guide issued by the Ministry of Education. According to this document, EAP teaching 
model needs to be adapted to go with the reform of teaching model, teaching content, teaching method and means. Most of the college students have 10-12 years of general English study, so academic English should be developed for the purpose of using English at the university level. The transition from EGP to EAP will definitely accelerate the pace of college English reform and achieving better teaching effects [8-11].

Secondly, EAP teaching conforms to the development of application-oriented colleges and universities. Dalian Polytechnic University is one of the universities that are the first batch of application-oriented colleges and universities in Liaoning Province. In order to follow the new requirements for the development of colleges and universities in the new era, Dalian Polytechnic University sets an accurate position of the university's education philosophy, deepen teaching reform, and carry out curriculum reform. The application of EAP teaching mode will greatly improve the quality of teaching, meet the needs of the society for talent cultivation, and contribute to the development of national and local economy.

In addition, English teachers also need to change their teaching styles and modes to effectively carry out academic English teaching. This can be achieved through frequent training and learning. Through short-term or long-term training, domestic and foreign visits, and development of professional English textbooks, teachers gradually change their concepts, update their concepts, explore new academic English teaching models combined, and innovate teaching methods to improve academic English teaching capabilities.

\section{Research-Led ACADEMIC English Course Design AND PRACTICE}

\section{A. EAP Teaching Mode}

First of all, the content-based teaching method is adopted in EAP teaching, and the training of language listening, speaking, reading and writing is combined with lecture, presentation, essay, reading comprehension, listening comprehension, debate, workshop and independent study. Classroom teaching focuses on the students' performance and student talking time of each class should be guaranteed. Students are divided into different groups according to their English level. What's more, the content and progress of EAP teaching are regularly adjusted. A multi-level English education system is adopted to integrate language, skills, professional knowledge, cultural background, and application ability learning.

Secondly, EAP teaching materials and content are regularly updated. The EAP textbooks and exercise books consist of four parts: listening, speaking, reading and writing. The content of the textbook is related to art and design, e.g. the connotation of colors, the application of science and technology in art and design, the creation process, academic paper writing specifications, art genres and other related materials. In the EAP teaching process, the teachers make the courseware according to the English levels of specific class. Teachers share courseware via emails, which fully expands teaching resources. On the basis of summarizing the existing teaching materials, it also classifies teaching materials according to the content and form, and establishes a database for teaching materials. These teaching materials are combined with network resources, supplemented by video and audio materials. The platform of Blackboard is adopted for teachers and students to share these resources.

In addition, the network learning platform is widely used to broaden the ways for students to carry out independent study, and carry out the reform of teaching methods. This can expand students' independent learning channels, ensure independent learning feedback, and improve the effect of independent learning. In order to improve students' independent learning ability, reasonable arrangement of students' independent learning content and form can effectively consolidate the teaching effect. A complete independent learning model is composed of "self-learning + teacher-guided self-learning + extracurricular self-learning and research-led projects". Students regularly check the learning tasks on Blackboard and make comments. Teachers interact with students to consolidate independent learning content in class. It can help students to make full use of selflearning time, carry out professional-related project creation under the guidance of English teachers, and improve English and professional ability at the same time.

\section{B. Research-led Project Design}

In most of the EAP class, the teacher assigns specific tasks and the students form into groups. Then, the members of the group will discuss and divide the work according to their own specialties, and formulate the next specific work steps based on primary and secondary research. Based on the information collected, members of the group conduct interviews or field research and propose reports according to specific projects. Some projects require members of the group to carry out design activities, which require students to brainstorm, generate design plans, develop specific design processes, modify their works under the guidance of instructors, and finally submit their works. Throughout the whole process of preparation, development, and verification stages of the research, students can get feedback and suggestions from their teachers at any time. In this process, the students' ability to independently carry out scientific research will be greatly improved. At the same time, students have also developed their capabilities to carry out research and cooperate with others, which is precisely the main ability that college students need to cultivate.

\section{SPECIFIC RESEARCH-LED PROJECTS}

The following examples are real research-led teaching and learning cases carried out by the Southampton International College of Dalian Polytechnic University. The English teaching materials for this Chinese-foreign cooperatively-run school are compiled and updated by all the teachers of the English module. Specific research-led projects are based on the teaching objectives of graphic arts and fashion design. These specific research-led tasks can effectively cultivate students' ability to carry out independent research, actively carry out teamwork, and develop expansive and divergent thinking in combination with their own majors.

\section{A. Shadow Puppet Show}

The EAP textbook contains a lot of things about the comparison and research of Chinese and Western cultures. The brief of this research-oriented project is that students will make a shadow puppet show. Firstly, students are divided into different groups. Then, after several rounds of discussion, they choose a play and divide the task into subtasks. The members of the group are responsible for screenwriting, props, dubbing, recording, editing, etc. Next, 
after several rounds of rehearsal, recording and editing, the final works will be uploaded to the designated website. Finally, on the website, the students have a heated discussion and exchanges of views. The project has fully mobilized students' interest in traditional Chinese culture. Through in-depth research on the history, development and themes of shadow puppet show, students select the play they are interested in, such as Mulan and Journey to the West or other stories with typical Chinese characteristics. This project fully motivates students' ability of doing research, language practice and video production. Fig. 1 shows the final performance of one shadow puppet show.

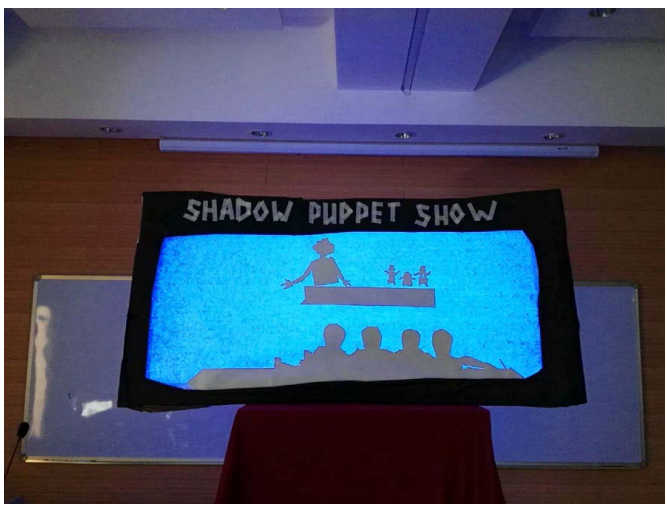

Fig.1. Shadow puppet show

\section{B. Bamboo Tower}

The assessment of the presentation is usually combined with the project-led research. Among the tasks, the bamboo tower project is a typical example since it is really useful for students to develop the sense of team spirit and creative ideas. The idea of bamboo tower comes from an English teacher, who has many years of experience in designing work related to bamboo. First, the teacher assigns tasks to the students. Then, after the students fully understand the main operating procedures of the project, they conduct relevant research and learn relevant words and expressions to describe the creative process. In the end, different groups work together to turn separate works into a large and complete one. This project helps students master the relevant terms to describe the artistic creation process and conduct artistic reflection, and provides a platform for students to carry out large-scale group research projects. Fig. 2 is the scene when all the participants put their works together into a large bamboo tower.

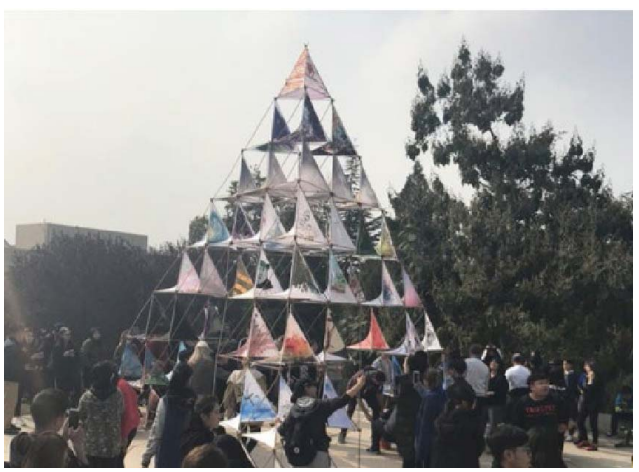

Fig.2. Bamboo tower

\section{Graffiti}

This Chinese-foreign cooperatively-run school between Dalian Polytechnic University and the University of Southampton has two majors: graphic arts and fashion design. The self-compiled EAP course books contain a lot of materials related to art design, art history, art genres, and design trends. One of the graffiti projects requires students to integrate different design symbols and elements to paint a graffiti wall. Participants of this project divide the work into several parts and complete the final graffiti work together. This research-led project effectively integrates students' language learning and design creation. The classroom is not restricted by the classroom, however, it allows students to fully experience the joy of artistic creation in the process of hands-on operation, and fully understand the graffiti. Such an art project contributes a lot to EAP teaching. Fig. 3 is the graffiti wall of the joint programme between Dalian Polytechnic University and the University of Southampton.

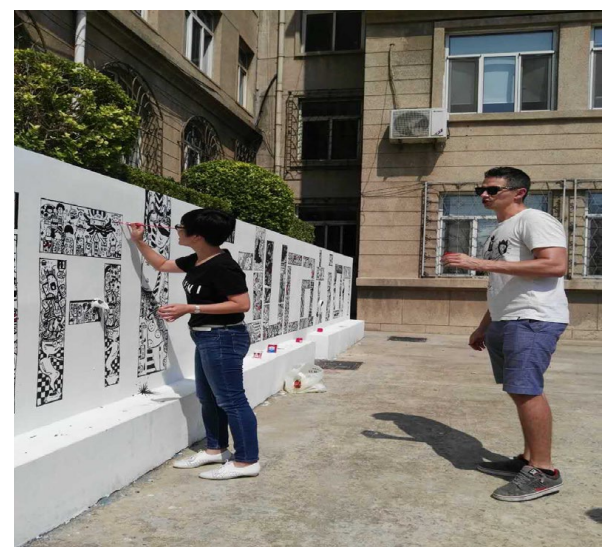

Fig.3. Graffiti

\section{Magazine}

Another research-led learning project is that students independently complete the entire process of material selection, interviews, image creation, illustration design, graphic layout, and color matching for a magazine to create a high-level art magazine. This project fully reflects the advantages of research-led teaching and learning. Under the guidance of teachers, students are divided into groups to conduct the following steps: material selection, in-depth field research, interviews, choosing pictures and drawing illustrations. They fully take advantage of their majors including graphic arts and fashion design and express their understandings of art and design in this magazine. After many rounds of revision, a high-level and highly professional magazine is created. Students of all grades can choose the theme that suits them according to their interests and English levels. This project can help students experience the various processes of magazine creation, fully integrate English learning with their majors, and make more students benefit from the group work. Fig. 4 shows three issues of magazine designed and published by students themselves. 

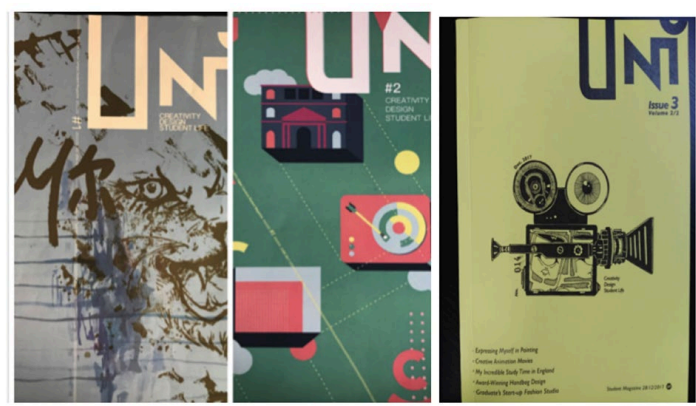

Fig. 4. Magazines

\section{CONCLUSION}

Based on the Chinese-foreign cooperatively-run school between Dalian Polytechnic University and the University of Southampton, this research combines EAP teaching models with EGP, exploring specific English teaching methods suitable for this cooperative education institution, and accelerates the transition of college English teaching from EGP to EAP. This change has effectively promoted the reform of college English teaching. Based on the existing teaching staff and teaching models in China, the academic English teaching of arts will be gradually promoted on a larger scale, and then extended to the reform of EAP teaching to other fields such as science, engineering, economics and management. This article analyzes the necessity of conducting EAP teaching in Chinese-foreign cooperatively-run schools, explains the components of selfcomplied EAP teaching materials, exemplifies the significance of research-led teaching and learning with several projects and suggests more practical ways to combine EAP teaching with research-led course design in other colleges and universities. Chinese-foreign cooperatively-run schools will enjoy a high speed of development in the future and the experiment of various teaching methods and strategies will provide more opportunities for these colleges and universities. Researchled teaching and learning can be widely employed in different disciplines to further promote the quality of Chinese-foreign cooperatively-run schools.

\section{REFERENCES}

[1] The Ministry of Education News: The Ministry of Education Approved the Termination of Some Chinese-foreign Cooperative Institutions. http://www.gov.cn. 5 July 2018.

[2] Q. Wen. "Problems and countermeasures on EGP and ESP in College English Teaching," Foreign Languages and Their Teaching, vol. 1, pp. $1-8,2014$.

[3] J. Cai. "The Orientation of College English Teaching Revisited: EGP and ESP," Journal of Zhejiang University (Humanities and Social Science), vol. 45, no. 4, pp. 83-93, 2015.

[4] S. Wang. "On Deepening the Reform in College English Teaching in China," Chinese Foreign Language, vol. 7, no. 2. pp. 7, 2010.

[5] S. Wang. "The Scientific View of College English Teaching Reform," Foreign Language World, vol. 6, pp. 9-14, 2013.

[6] B. Zamorski. "Research-led Teaching and Learning in Higher Education: A case," Teaching in Higher Education, vol. 7, no. 4, pp. 411-427, 2002.

[7] M. Haaker and B. "Morgan-Brett. Developing Research-led Teaching: Two Cases of Practical Data Reuse in the Classroom," SAGE, pp. 1-9, 2017.

[8] X. Wang and S. Yan. "Study on the Integrated Teaching Mode of ESP and EGP in College English for Art Majors --- A Case Study of Beijing City University College English for Art Majors," Education Teaching Forum, no. 48, pp. 225-226, 2016.

[9] Y. Wu. "Reflections on Opening Characteristics English Courses in Arts Colleges and Universities: A Preliminary ESP Teaching Exploration Based on CBI," Foreign Language Translation, 2014.

[10] F. Zhang. "The Path to University English Teaching Reform: An Interview with Professor Wang Lifei," Shangdong Foreign Language Teaching, vol. 36, no. 2, pp. 3-8, 2015.

[11] D. Shu. "Foreign Language Academic Research Should Adapt to National Development Strategies and Meet Social Needs," Foreign Language Learning Theory and Practice, vol. 3, pp. 1-5, 2015. 